\title{
G protein-coupled estrogen receptor GPR30 exerts vasoprotective effects in apolipoprotein E-deficient mice
}

\section{Type}

Research paper

\section{Keywords}

atherosclerosis, reactive oxygen species, glucose tolerance, G-1, G protein-coupled receptor 30 , angiotensin II type 1 receptor

\begin{abstract}
Introduction

GPR30 is an intracellular transmembrane $G$ protein-coupled receptor that mediates non-genomic estrogen signaling. The GPR30 agonist G-1 modulates glucose homeostasis and vascular function. However, its impact on vascular inflammation and atherogenesis has not yet been investigated in the atherosclerotic apolipoprotein E-deficient(ApoE-/-) mouse model.
\end{abstract}

Material and methods

ApoE-/- mice were fed a high-cholesterol diet for 7 weeks while being treated with the selective GPR30 agonist G-1 ( $n=6-7)$. After the treatment period, vascular relaxation capacity, vascular oxidative stress, and atherosclerotic plaque burden were assessed. In vitro, reactive oxygen species, expression levels of the angiotensin II type1(AT1) receptor, and proliferation rate were quantified in human coronary artery smooth muscle cells(HCASMC).

\section{Results}

G-1 significantly improved glucose tolerance in vivo $(142.2 \pm 8.1 \mathrm{mg} / \mathrm{dl}$ vs. $204.6 \pm 13.3 \mathrm{mg} / \mathrm{dl})$, G-1 reduced vascular oxidative stress $(221 \pm 88 \mathrm{RLU} / \mathrm{s} / \mathrm{mg}$ vs.1,983 $\pm 885 \mathrm{RLU} / \mathrm{s} / \mathrm{mg})$ and improved endothelium-dependent vasodilation (relaxation to $35.1 \pm 4.5 \%$ vs. $63.0 \pm 4.6 \%$ ). Furthermore, treatment with G-1 significantly reduced the atherosclerotic plaque burden of female ApoE-/- mice $(56.5 \pm 3.7 \%$ vs. $75.5 \pm 2.9 \%$ ). In vitro, G-1 provoked a significant downregulation of the AT1 receptor in HCASMC (0.67 \pm 0.09 -fold). Furthermore, G-1 blunted angiotensin II-induced ROS production by HCASMC $(817 \pm 7 \mathrm{RLU} / \mathrm{s} / \mathrm{mg}$ vs. $1,625 \pm 105 \mathrm{RLU} / \mathrm{s} / \mathrm{mg})$ and diminished HCASMC proliferation $(-26.8 \pm 2.7 \%$ vs. $+50.4 \pm 1.7 \%)$.

\section{Conclusions}

Selective GPR30 activation improves glucose tolerance in vivo and decreases vascular ROS production in vitro and in vivo. In vitro, the antioxidant effect might be mediated by downregulation of the AT1 receptor. In vivo, the antioxidant effect of G-1 is associated with an improved endothelial function and a reduced atherosclerotic plaque burden in ApoE-deficient mice, indicating beneficial vascular effects of GPR30 activation. GPR30 agonism might thus be a compelling treatment strategy against atherosclerosis. 


\section{G protein-coupled estrogen receptor GPR30 exerts vasoprotective effects in apolipoprotein E-deficient mice}

Julian Jehle*,1, Ulrich M. Becher ${ }^{\star, 1}$, Moritz Nöthel ${ }^{1}$, Sandra Adler ${ }^{1}$, Katharina Groll' ${ }^{1}$, Georg Nickenig ${ }^{1}$, and Vedat Tiyerili ${ }^{1}$

${ }^{1}$ Department of Internal Medicine II, Cardiology, Pneumology, Angiology, University Hospital Bonn, Bonn, Germany

*These authors contributed equally to this work.

Running head: GPR30 is vasoprotective in $\mathrm{ApoE}^{-/-}$mice

Corresponding author: Julian Jehle

Venusberg-Campus 1

Building 13

53127 Bonn

Germany

Tel: +4922828751484

Fax: +49228 28751482

Email: julian.jehle@ukbonn.de 
Abstract:

Introduction: GPR30 is an intracellular transmembrane G protein-coupled receptor that mediates non-genomic estrogen signaling. The GPR30 agonist G-1 modulates glucose homeostasis and vascular function. However, its impact on vascular inflammation and atherogenesis has not yet been investigated in the atherosclerotic apolipoprotein E-deficient $\left(\mathrm{ApoE}^{-/}\right)$mouse model.

Material and methods: ApoE ${ }^{-/}$mice were fed a high-cholesterol diet for 7 weeks while being treated with the selective GPR30 agonist G-1 $(n=6-7$ of either sex and treatment group). After the treatment period, vascular relaxation capacity, vascular oxidative stress, and atherosclerotic plaque burden were assessed. In vitro, reactive oxygen species, expression levels of the angiotensin II type 1 (AT 1 ) receptor, and proliferation rate were quantified in human coronary artery smooth muscle cells (HCASMC).

Results: G-1 significantly improved glucose tolerance in vivo $(142.2 \pm 8.1 \mathrm{mg} / \mathrm{dl}$ vs. $204.6 \pm 13.3 \mathrm{mg} / \mathrm{dl}), \mathrm{G}-1$ reduced vascular oxidative stress $(221 \pm 88 \mathrm{RLU} / \mathrm{s} / \mathrm{mg}$ vs. $1,983 \pm 885 \mathrm{RLU} / \mathrm{s} / \mathrm{mg}$ ) and improved endothelium-dependent vasodilation (relaxation to $35.1 \pm 4.5 \%$ vs. $63.0 \pm 4.6 \%$ ). Furthermore, treatment with G-1 significantly reduced the atherosclerotic plaque burden of female $\mathrm{ApoE}^{-/-}$mice $(56.5 \pm$ $3.7 \%$ vs. $75.5 \pm 2.9 \%$ ). In vitro, G-1 provoked a significant downregulation of the $\mathrm{AT}_{1}$ receptor in HCASMC $(0.67 \pm 0.09$-fold $)$. Furthermore, G-1 blunted angiotensin IIinduced ROS production by HCASMC ( $817 \pm 7 \mathrm{RLU} / \mathrm{s} / \mathrm{mg}$ vs. $1,625 \pm 105 \mathrm{RLU} / \mathrm{s} / \mathrm{mg}$ ) and diminished HCASMC proliferation (-26.8 $\pm 2.7 \%$ vs. $+50.4 \pm 1.7 \%)$.

Conclusion: Selective GPR30 activation improves glucose tolerance in vivo and decreases vascular ROS production in vitro and in vivo. In vitro, the antioxidant effect 
might be mediated by downregulation of the $\mathrm{AT}_{1}$ receptor. In vivo, the antioxidant effect of G-1 is associated with an improved endothelial function and a reduced atherosclerotic plaque burden in ApoE-deficient mice, indicating beneficial vascular effects of GPR30 activation. GPR30 agonism might thus be a compelling treatment strategy against atherosclerosis.

Key words:

G-1; G protein-coupled receptor 30; atherosclerosis; glucose tolerance; reactive oxygen species; angiotensin II type 1 receptor. 
Abbreviations list:

Akt

ApoE

AT 1 receptor

$E R \alpha / \beta$

G-1

GPER

GPR30

HCASMC

ipGTT

MAPK

MNAR

NO

PI3K

ROS
Protein kinase $B$

Apolipoprotein $\mathrm{E}$

Angiotensin II type 1 receptor

Estrogen receptor $\alpha / \beta$

GRP30 agonist

G protein-coupled estrogen receptor $=$ GPR30

G protein-coupled receptor $30=$ GPER

Human coronary artery smooth muscle cells

Intraperitoneal glucose tolerance test

Mitogen-activated protein kinase

Modulator of nongenomic activity of the ER

Nitric oxide

Phosphatidylinositol 3-kinase

Reactive oxygen species 


\section{Introduction}

Sex steroid hormones and their receptors have been shown to determine cardiovascular gender differences [1]. While estrogen and its derivatives protect premenopausal women from atherosclerosis and cardiovascular disease, there is a steep increase in the risk for hypertension and coronary heart disease following menopause [2]. Estrogen receptors ER $\alpha$ and ER $\beta$ are nuclear receptors that transmit genomic estrogen signaling. However, several of the cardioprotective effects of estrogen have been attributed to non-genomic signaling pathways. Classic genomic signaling occurs by the regulation of gene transcription. In brief, hormone binding to the nuclear receptor, which in turn binds to co-regulators and interacts with a hormone response element ( $\mathrm{HRE}$ ), leads to an increase of gene transcription. Meanwhile, non-genomic signaling takes place at the plasma membrane, where nuclear receptors activate kinase pathways, which subsequently leads to downstream cellular events. Both pathways often converge or regulate each other [3]. The observation of non-genomic estrogen receptor signaling has fostered the theory of a membrane-bound version of the ER receptor that activates phosphatidylinositol 3-kinase (PI3K)/ protein kinase B (Akt) - mitogen-activated protein kinase (MAPK) signaling via adaptor molecules, such as modulator of nongenomic activity of the ER (MNAR) or caveolin-1 and $2[4,5,6]$. Moreover, rapid, non-genomic estrogen signaling has been attributed to the seven-transmembrane $G$ protein-coupled receptor GPR30 / GPER. GPR30 was first discovered in human endothelial cells and is expressed throughout the cardiovascular system in women and men $[7,8]$. The development of a selective GPR30 agonist, G-1, and a selective GPR30 antagonist, G-15, as well as the use of GPR30 knockout mice, have opened 
up a whole research area around the implications of GPR30 in metabolic and cardiovascular health $[9,10]$.

Signaling through GPR30 involves the activation of the epidermal growth factor receptor (EGFR) and nonreceptor tyrosine kinases of the Src (Sarcoma Plymouth Rock chicken) family. Furthermore, activation of GPR30 triggers intracellular accumulation of cAMP, mobilization of calcium, and activation of PI3K $[11,12]$.

Meanwhile, an ever-growing body of evidence has shown that GPR30 can modulate vasodilation in various models $[8,13,14,15,16]$, lower arterial blood pressure $[13,14,15,17]$, reduce inflammation in the ischemia/reperfusion model [18], and promote glucose tolerance and insulin sensitivity $[16,17,19,20]$. In the referred studies, vasodilation was induced by i.v., s.c., or ex vivo administration of G-1, arterial blood pressure was studied after G-1 administration or in GPR30-- mice. In the model of ischemia and reperfusion, GPR30 was antagonized by G-15 and glucose tolerance was assessed in pharmacological and genetic experimental setups in mice and humans. One study has also shown that G-1 prevents atherogenesis in a feeding model of wildtype mice [21]. However, there is currently no study that coherently evaluates the metabolic, vasoactive, and anti-atherogenic properties of G1 in the apolipoprotein E-deficient mouse model $\left(\mathrm{ApoE}^{-/-}\right)$, which is a standard model for murine atherogenesis [22]. We therefore studied ROS production, vascular function, and atherosclerotic plaque burden in $\mathrm{ApoE}^{-/-}$mice, following a highcholesterol diet and G-1 treatment for 7 weeks. Additionally, the impact of G-1 on ROS production and cell proliferation was evaluated in vitro in primary human coronary artery smooth muscle cells (HCASMC). We hypothesized that G-1 reduces arterial blood pressure, improves glucose tolerance and reduces the atherosclerotic plaque burden of $\mathrm{ApoE}^{-/-}$mice. 


\section{Materials and methods}

$\mathrm{ApoE}^{--}$mice of both sexes with a C57BL/6 genetic background were used in the present study. Mice were purchased from Charles River Laboratories (Wilmington, USA).

Animals were maintained at a room temperature of $22^{\circ} \mathrm{C}$ and a 12-hour dark-lightcycle. Animals had unrestricted access to drinking water and rodent chow. Treatment protocols were in accordance with institutional guidelines and German animal protection laws. All experiments were approved by the North Rhine Westphalian State Agency for Nature, Environment and Consumer Protection, which considered the ethics and animal welfare aspects in their approval.

Female $\mathrm{ApoE}^{-/-}$mice were ovariectomized at the age of 8 weeks in order to exclude confounding effects from endogenous estrogen and to surgically induce menopause. Ovariectomy was performed as described previously [23]. Briefly, peritoneal access was gained via a dorsal midline incision. After a blunt dissection of the underlying connective tissue and fasciae, the ovaries were identified in the visceral adipose tissue and the uterine horns and ovarian vessels were ligated. Hereafter, both ovaries were excised, and the wound was closed with a simple interrupted suture.

The effect of G-1 on male mice, which also express the GPR30 receptor, was studied in an independent cohort. At 12 weeks, female and male mice were fed a high-fat and high-cholesterol diet containing $21 \%(\mathrm{w} / \mathrm{w})$ fat, $19.5 \%(\mathrm{w} / \mathrm{w})$ casein, and $1.25 \%$ (w/w) cholesterol (Ssniff, Soest, Germany) for seven weeks. Concomitantly, mice were subjected to s.c. injections of the selective GPR30 agonist G-1 [50 $\mu \mathrm{g} / \mathrm{kg}$ 
bodyweight and a volume of $5 \mu \mathrm{l} / \mathrm{g}$ bodyweight] every other day in the treatment group $(n=6-7$ of either sex) or to vehicle (DMSO $[0.5 \%(v / v)])$ in the control group ( $n$ $=6-7$ of either sex). At the end of the treatment period, G-1-treated mice were compared to the respective vehicle-treated controls. The experimental protocol is depicted in Fig. 1.

2.1 Body weight, plasma cholesterol, blood pressure, and heart rate

Mice were weighed weekly using a Kern EW 3000-2M balance (Kern \& Sohn GmbH, Balingen, Germany).

Blood was drawn from the inferior vena cava of the sacrificed mice using a heparinized syringe and a 26G needle. Plasma cholesterol levels were assessed by gas chromatography-flame ionization detection, as reported earlier [24].

Blood pressure and heart rate were measured non-invasively using a tail cuff device (Coda 6, Kent Scientific Corporation, Torrington, USA) as described [25]. Mice were acclimated to the volume-pressure recording device for three consecutive days. Thereafter, blood pressure and heart rate were recorded on the 3 consecutive days that followed the habituation period. The mean values for these three days were calculated for each mouse.

2.2 Fasting blood glucose and intraperitoneal glucose tolerance test

Mice were starved overnight for 13 hours and fasting blood glucose levels were assessed on the next morning using a blood glucose meter (Accu-Chek ${ }^{\circledR}$, Roche Diagnostics Deutschland GmbH, Mannheim, Germany). 
An intraperitoneal glucose tolerance test (ipGTT) was performed after six weeks of high-fat diet and G-1- versus vehicle treatment. Mice were challenged with an i.p. injection of $2 \mathrm{~g} / \mathrm{kg}$ glucose. Blood glucose levels were measured at baseline and at time points $15,30,45$, and 60 minutes after the injection.

\subsection{Endothelium-dependent vasodilation}

After seven weeks of high-fat diet and G-1/vehicle treatment, mice were sacrificed by cervical dislocation under $5 \%(\mathrm{v} / \mathrm{v})$ isoflurane anesthesia (Abbott Laboratories, Chicago, USA).

The descending thoracic aorta was carefully excized and vascular contractility and endothelium-dependent vasodilation were measured. For this purpose, the vessel was transferred into $37^{\circ} \mathrm{C}$ warm Tyrode's solution containing $118.0 \mathrm{mM} \mathrm{NaCl}, 2.5$ $\mathrm{mM} \mathrm{CaCl} 2,4.73 \mathrm{mM} \mathrm{KCl}, 1.2 \mathrm{mM} \mathrm{MgCl}_{2}, 1.2 \mathrm{mM} \mathrm{KH}_{2} \mathrm{PO}_{4}, 25.0 \mathrm{mM} \mathrm{NaHCO}_{3}, 0.026$ $\mathrm{mM}$ NaEDTA, $5.5 \mathrm{mM} \mathrm{D}(+)$ glucose, adjusted to $\mathrm{pH} 7.40$. Then, the thoracic aorta was cut into $3 \mathrm{~mm}$ thick rings which were carefully hooked to a myograph in an organ bath (IOA-5301, FMI GmbH, Seeheim, Germany). The organ bath was perfused with oxygenated Tyrode's solution. $40 \mathrm{mM} \mathrm{KCl}$ was applied to elicit smooth muscle cell depolarization and subsequent vasoconstriction.

Hereafter, $\mathrm{KCl}$ was washed out and increasing concentrations of phenylephrine (to a maximum concentration of $100 \mu \mathrm{M})$ induced vasoconstriction. Endotheliumdependent vasodilation was then induced by increasing concentrations of carbachol (to a maximum concentration $100 \mu \mathrm{M}$ ). Endothelium-independent vasodilation was assessed as a procedural control and was induced by nitroglycerine (maximum concentration $10 \mu \mathrm{M})$. 
2.4 Reactive oxygen species formation

Vascular production of reactive oxygen species was quantified by L-012 chemiluminescence in a scintillation counter (Lumat LB 9501, Berthold Technologies GmbH \& Co. KG, Wildbad, Germany). L-012 stock solution (Wako Chemicals GmbH, Neuss, Germany) was diluted in PBS (1:100) and added to modified KH-HEPESbuffer (1:10), containing $99.01 \mathrm{mM} \mathrm{NaCl}, 4.69 \mathrm{mM} \mathrm{KCl}, 1.87 \mathrm{mM} \mathrm{CaCl}, 1.20 \mathrm{mM}$ $\mathrm{MgSO}_{4}, 20.0 \mathrm{mM}$ NaHEPES, $1.03 \mathrm{mM} \mathrm{K} \mathrm{HPO}_{4}, 25.0 \mathrm{mM} \mathrm{NaHCO}, 11.1 \mathrm{mM}$ $\mathrm{D}(+)$ glucose, adjusted to $\mathrm{pH} 7.40$. Two $3 \mathrm{~mm}$ thick rings from the proximal and the distal end of the thoracic aorta were transferred into $200 \mu \mathrm{l}$ of the L-012 working solution and chemiluminescence was assessed over 10 minutes in 1-minuteintervals. The scintillation count was normalized to the weight of the tissue sample. 5minute scintillation counts were used for statistical analyses.

2.5 In vivo analysis of GRP30- and angiotensin II type 1 (AT 1 ) receptor expression by qPCR

Expression of GRP30- and angiotensin II type 1 (AT1) receptors was analyzed by quantitative Fast Real-Time PCR on lysed aortic tissue of mice from both sexes and treatment groups. Aortic tissue was harvested and lysed in $1 \mathrm{ml}$ Trizol® reagent using a Schuett homogen plus tissue lyser (Schuett-biotec GmbH, Göttingen, Germany) as reported earlier [24]. $200 \mu \mathrm{l}$ chloroform (Merck, Darmstadt, Germany) were added to each sample and the phases were separated by centrifugation $\left(18,000 \times \mathrm{xg} ; 4^{\circ} \mathrm{C} ; 15\right.$ minutes). $200 \mu \mathrm{l}$ isopropanol were then added to elicit RNA precipitation. The precipitated RNA was then washed with ethanol $[75 \%(\mathrm{v} / \mathrm{v})]$, dried, and resuspended 
in RNAse-free water. RNA was reversely transcribed using the Omniscript RT kit (Qiagen $\mathrm{GmbH}$, Hilden, Germany). qPCR analyses were performed using TaqMan® probes (Thermo Fisher Scientific Inc.) and a 7500 Fast Real-Time PCR system and 7500 software v.2.0.6 (both Thermo Fisher Scientific Inc.). TaqMan® probes used in this study are detailed in Table 1.

2.6 Histological quantification and characterization of atherosclerotic plaques

Hearts of G-1-treated $\mathrm{ApoE}^{-/-}$mice and vehicle-treated controls were excized and embedded upright in tissue freezing medium. The aortic valve was positioned horizontally, and the hearts were frozen at $-80^{\circ} \mathrm{C}$. Then, the aortic root was sliced using a Leica CM 1900 cryostat (Leica Biosystems GmbH, Wetzlar, Germany) at a thickness of $8 \mu \mathrm{m}$ per section. Tissue slices were recovered on poly-lysine-covered object slides (Thermo Fisher Scientific, Inc., Waltham, USA) and stained for histological evaluation. Sections, on which all three cusps of the aortic valve could be identified, were used for histological plaque analyses. On average, 4 sections per heart were analyzed, spanning a distance of $320 \mu \mathrm{m}$.

Then, oil red $\mathrm{O}$ staining was performed to visualize atherosclerotic plaques. $0.5 \%$ $(w / v)$ oil red $O$ in an isopropanol stock solution was diluted with deionized water to a final concentration of $0.3 \%(\mathrm{w} / \mathrm{v})$. Slides were thawed and dried at room temperature. Histological samples were dehydrated with $60 \%(\mathrm{v} / \mathrm{v})$ isopropanol for 5 minutes before being exposed to the $0.3 \%(\mathrm{w} / \mathrm{v})$ oil red $\mathrm{O}$ working solution for 15 minutes. Hereafter, slides were rinsed with deionized water and histological slices were costained with haematoxylin (Carl Roth $\mathrm{GmbH}$, Karlsruhe, Germany) for 30 seconds. 
Finally, slides were washed with lukewarm tap water and sealed with cover slips using Aquatex mounting agent (Merck Millipore, Darmstadt, Germany).

Microscopic pictures were taken using a Zeiss Axiovert 200M microscope (Carl Zeiss Jena $\mathrm{GmbH}$, Jena, Germany) and Axiovision 4.8 software (Carl Zeiss Jena GmbH). Percentage of plaque burden was calculated as oil red O-positive areas divided by the total area of the vessel wall. Treatment group affiliation was blinded prior to histological assessment.

2.7 Immunohistochemical staining of GRP30 in vascular tissue

Expression of GPR30 was assessed immunohistochemically in the abdominal aorta of male and female $\mathrm{ApoE}^{-/-}$mice. Aortic tissue was embedded in tissue freezing medium (Leica Biosystems $\mathrm{GmbH}$, Wetzlar, Germany) and snap frozen at $-80^{\circ} \mathrm{C}$. Frozen sections were obtained using a Leica CM 1900 cryostat (Leica Biosystems $\mathrm{GmbH}$, Wetzlar, Germany). Expression of GPR30 was assessed by immunohistochemical staining (primary antibody: a-GPR30, Rabbit, IgG, Abcam, Cambridge, UK) secondary antibody: Cy3, Goat Anti-Rabbit IgG, Abcam, Cambridge, UK). Slides were fixed in acetone for 20 minutes at room temperature, then washed in PBS and blocked in 2\% BSA in PBS for 30 minutes. Afterwards, sections were incubated at room temperature for 1 hour with the primary antibody, which had been diluted by 1:100 in blocking solution. Afterwards, slides were washed with PBS and the secondary antibody, which had been diluted by 1:500 in PBS, was administered at room temperature in the dark for 1 hour. Afterwards, slides were fixed and nuclei were stained using Vectashield mounting medium with DAPI (Vector Laboratories). Microphotographic pictures were taken using a Zeiss Axiovert 200M microscope 
(Carl Zeiss Jena GmbH, Jena, Germany) and Axiovision 4.8 software (Carl Zeiss Jena $\mathrm{GmbH})$.

\subsection{Cell culture}

Primary human coronary artery smooth muscle cells (HCASMC) were purchased from PromoCell (Heidelberg, Germany) and cultivated in phenol red-free smooth muscle cell basal medium (PromoCell) and the appropriate supplement mix containing fetal calf serum at a final concentration of $0.05 \mathrm{ml} / \mathrm{ml}$, epidermal growth factor [0.5 ng/ml], basic fibroblast growth factor [2 $\mathrm{ng} / \mathrm{ml}]$, and insulin $[5 \mu \mathrm{g} / \mathrm{ml}]$ as described [26]. Experiments were carried out at $80 \%$ confluence and at passages six through eight.

mRNA expression levels of the AT 1 receptor were quantified using $\mathrm{QPCR}$ as follows. HCASMC were stimulated with the GPR30 agonist G-1 $[1 \mu \mathrm{M}]$ for 4 hours. At a concentration of $1 \mu \mathrm{M}, \mathrm{G}-1$ has been described to bind highly selective to GPR30 with no relevant binding to ERa and ERß [9]. Controls were stimulated simultaneously with DMSO $[0.1 \%(\mathrm{v} / \mathrm{v})]$. Thereafter, cells were rinsed with PBS and lysed with Trizol $\circledast$ as described before [27]. RNA precepitation and extraction was performed as described above for aortic tissue. TaqMan® probes used in this study are detailed in Table 1.

L-012 working solution was prepared freshly, as described for the ex vivo measurement of reactive oxygen species from vascular tissue (see 2.4). HCASMC 
were stimulated with $\mathrm{G}-1[1 \mu \mathrm{M}]$, angiotensin $\mathrm{II}[1 \mu \mathrm{M}]$, or both for 4 hours. DMSO $[0.1 \%(v / v)]$ served as a control. Cells were washed with PBS and harvested using trypsin $[0.05 \%(w / v)]$ for 5 minutes. Cells were collected and counted by using a Neubauer counting chamber (Brand $\mathrm{GmbH}$, Wertheim, Germany). Thereafter, cells were centrifuged (170xg, 5 minutes) and reconstituted in $100 \mu \mathrm{L}$-012 working solution, and ROS were detected with a Lumat LB 9501 scintillation counter. Events were normalized to the cell count. 5-minute scintillation counts were used for statistical analyses.

HCASMC proliferation was quantified using a colorimetric 5-bromo-2'-deoxyuridine (BrdU) ELISA, according to the manufacturer's instructions (BrdU Cell Proliferation ELISA kit (colorimetric), Abcam, Cambridge, UK). HCASMC were cultured in 96-well plates and assayed at 70-80\% confluence. In brief, cells were stimulated with G-1 [1 $\mu \mathrm{M}]$, angiotensin II [1 $\mu \mathrm{M}]$, or both for 24 hours. DMSO $[0.1 \%(\mathrm{v} / \mathrm{v})]$ served as a control. After stimulation, replicating DNA was labeled with the BrdU reagent supplied with the kit for 4 hours. Cells were fixed, permeabilized, and tagged with a BrdU antibody and a horseradish peroxidase-conjugated secondary antibody. The latter catalysed a colorimetric reaction upon addition of the chromogenic substrate tetramethylbenzidine (TMB), which was quantified using a microplate reader (Infinite M200, Tecan, Männedorf, Switzerland).

\subsection{Statistical analyses}

Data are presented as the mean \pm SEM. Analyses were performed using Microsoft Excel software (Microsoft, Redmond, USA) and GraphPad Prism (GraphPad 
Software, San Diego, USA). Continuous variables of two groups were compared using unpaired Student's two-sided t-test. For the comparison of three or more groups, a one-way ANOVA and subsequent Bonferroni correction was performed. Pvalues $<0.05$ were considered statistically significant. Effect sizes were estimated from the published results of similar studies. Meyer and co-workers found a $\sim 45 \%$ reduction in the atherosclerotic plaque burden in G-1-treated wildtype mice compared to vehicle-treated controls [19]. The sample size was calculated using $G^{*}$ Power software (Franz Faul, University of Kiel, Germany) with a prespecified alpha error probability of 0.05 and a prespecified power ( 1 - beta error probability) of 0.95 .

3. Results

3.1 G-1 treatment does not alter arterial blood pressure, heart rate, body weight, or total cholesterol in atherosclerotic ApoE ${ }^{-1-}$ mice

Arterial blood pressure of male $\mathrm{ApoE}^{-/-}$mice and female ovariectomized $A p o \mathrm{E}^{-/-}$mice was assessed after seven weeks of G-1- versus vehicle treatment. As detailed in Table 2, G-1 treatment did not change arterial blood pressure compared to vehicletreated control animals. Likewise, G-1 treatment did not affect murine heart rate, body weight, or total cholesterol levels (Table 2).

3.2 G-1 improves both, fasting blood glucose and glucose tolerance in vivo Insulin sensitivity was measured by fasting blood glucose and i.p. glucose tolerance tests (ipGTT). After six weeks of G-1 treatment, fasting blood glucose levels were 
significantly lower in female ovariectomized $\mathrm{Apo}^{-/-}$mice compared to vehicle-treated controls $(111.8 \pm 2 \mathrm{mg} / \mathrm{dl}$ versus $126.8 \pm 4 \mathrm{mg} / \mathrm{dl} ; n=4-5 ; p=0.0450$; Fig. 2a). Among male $\mathrm{ApoE}^{-/-}$mice, there was a tendency towards lower fasting blood glucose levels within the G-1-treated group compared to the control group, however, the difference did not reach statistical significance $(101 \pm 9 \mathrm{mg} / \mathrm{dl}$ versus $119 \pm 10 \mathrm{mg} / \mathrm{dl}$; $n=4-5 ; p>0.05 ;$ Fig. 2b).

On ipGTT, mice of both sexes showed significantly improved glucose tolerance after G-1 treatment, compared to the vehicle control. After an i.p. challenge with $2 \mathrm{~g} / \mathrm{kg}$ glucose, female mice of the G-1 treatment group quickly recovered from peak blood glucose levels and reached $142.2 \pm 8.1 \mathrm{mg} / \mathrm{dl}(n=5)$ within 30 minutes. Meanwhile, blood glucose levels were still significantly elevated in the female control group, 30 minutes after the glucose challenge (204.6 $\pm 13.3 \mathrm{mg} / \mathrm{dl} ; n=5 ; p=0.0039 ;$ Fig. $2 \mathrm{c})$. Male $\mathrm{ApoE}^{-/-}$mice peaked a little higher than female mice and euglycemia was not restored within 60 minutes in both treatment groups. However, glucose tolerance of G-1-treated male mice was also improved compared to controls, which resulted in a significantly lower blood glucose level at 30 and 45 minutes after the glucose challenge $(252.5 \pm 5.6 \mathrm{mg} / \mathrm{dl}$ versus $283.7 \pm 8.8 \mathrm{mg} / \mathrm{dl} ; \mathrm{n}=4 ; \mathrm{p}=0.0250(30$ minutes); $222.3 \pm 3.7 \mathrm{mg} / \mathrm{dl}$ versus $273.7 \pm 14.5 \mathrm{mg} / \mathrm{dl} ; \mathrm{n}=4 ; \mathrm{p}=0.0105$ (45 minutes) Fig. 2d).

3.3 G-1 enhances endothelium-dependent vasodilation and diminishes vascular ROS formation

Vascular contractility and endothelium-dependent vasodilation of the thoracic aorta were studied in an organ bath after seven weeks of high-fat diet and G-1- versus 
vehicle treatment. Vasoconstriction was triggered by phenylephrine in terms of concentration-responses. Vasoconstriction was similar between treatment groups among both sexes (Fig. 3a-b).

Endothelium-dependent vasodilation was elicited by increasing concentrations of carbachol. In female ovariectomized $\mathrm{ApoE}^{-/-}$mice, G-1 treatment significantly improved endothelium-dependent vasodilation compared to vehicle. At a carbachol concentration of $10^{-5} \mathrm{M}, \mathrm{G}-1$-treated mice displayed an average relaxation to $40.3 \pm$ $5.5 \%(n=6)$ compared to only $63.0 \pm 8.0 \%(n=5 ; p=0.0399)$ in the control group and at $10^{-4} \mathrm{M}$ carbachol, G-1-treated mice displayed an average relaxation to $35.1 \pm$ $4.5 \%(n=6 ; G-1)$ compared to only $63.0 \pm 4.6 \%(n=5 ; p=0.0021$; control; Fig. 3c). Such differences were not apparent in male $\mathrm{ApoE}^{-1-}$ mice, where G-1-treated animals showed no improvement in endothelium-dependent vasodilation compared to vehicle-treated controls (Fig. 3d).

The effects of G-1 treatment on vascular relaxation were mirrored by vascular reactive oxygen species formation. G-1-treated female ovariectomized $\mathrm{ApoE}^{-/-}$mice showed a dramatic decrease in ROS formation compared to vehicle-treated controls $(221 \pm 88 \mathrm{RLU} / \mathrm{s} / \mathrm{mg}$ vs. $1,983 \pm 885 \mathrm{RLU} / \mathrm{s} / \mathrm{mg} ; n=5-7 ; p=0.0387$, Fig. 3e). Meanwhile, G-1 treatment caused no significant reduction in ROS production in male ApoE ${ }^{-/}$mice $(2,679 \pm 1,700 \mathrm{RLU} / \mathrm{s} / \mathrm{mg}$ vs. $1,708 \pm 546 \mathrm{RLU} / \mathrm{s} / \mathrm{mg} ; \mathrm{n}=5 ; \mathrm{p}>0.05$ Fig. 3f).

3.4 G-1 treatment alleviates the atherosclerotic plaque burden of $\mathrm{Apo}^{-/-}$mice

The atherosclerotic plaque burden was assessed in frozen cross-sections through the aortic sinus. ApoE ${ }^{-/}$mice, which had been treated with the selective GPR30 
agonist G-1, showed a markedly reduced atherosclerotic plaque burden compared to vehicle-treated controls. This effect reached statistical significance in female ovariectomized $\mathrm{ApoE}^{-/-}$mice, where oil red $\mathrm{O}$ positive areas yielded $56.5 \pm 3.7 \%(\mathrm{n}=$ 6 ; G-1) versus $75.5 \pm 2.9 \%(n=4 ; p=0.0065$; control; Fig. $4 a)$ of the total vessel area. Among male ApoE ${ }^{-/-}$mice, oil red O positive areas yielded $44.6 \pm 7.4 \%(n=5$; G-1) and $52.3 \pm 4.0 \%(n=5 ; p>0.05$; control; Fig. $4 b)$.

3.5 GPR30 is not expressed in resident vascular cells of the murine aorta

Since gender differences in the expression of GPR30 may account for the observed differences in the effect of G-1 on endothelial function and atherogenesis, we studied the expression of GPR30 in aortic tissue of female and male ApoE ${ }^{-/}$mice. Both by qPCR and by immunohistochemistry, GPR30 was undetectable in the aortic tissue, irrespective of gender (Supplementary Fig. S1). Expression of the AT 1 receptor was not altered in aortic tissue from female and male $\mathrm{ApoE}^{-/-}$mice treated with $\mathrm{G}-1$ as compared to vehicle-treated controls (female DMSO vs G1: $1.00 \pm 0.28$ vs. $2.52 \pm$ 1.20-fold; $n=3 ; p>0.05$; male DMSO vs. G1: $0.52 \pm 0.17$ vs. $0.59 \pm 0.08$-fold; $n=5$; $p>0.05)$.

3.5 G-1 diminishes AT1 receptor expression in HCASMC and mitigates angiotensindriven HCASMC proliferation and ROS production

Finally, the effects of the selective GPR30 agonist G-1 on HCASMC biology were assessed in vitro. 
HCASMC were stimulated with G-1 $[1 \mu \mathrm{M}]$ for four hours, which caused a significant decrease in $\mathrm{AT}_{1}$ receptor mRNA expression levels compared to vehicle $(0.67 \pm 0.09$ fold; $n=10 ; p=0.0246$; Fig. 5a).

Hereafter, HCASMC were stimulated with G-1 [1 $\mu \mathrm{M}]$, angiotensin II [1 $\mu \mathrm{M}]$, or both for four hours and ROS formation was quantified. G-1 significantly reduced baseline ROS formation compared to the control $(529 \pm 69 \mathrm{RLU} / \mathrm{s} / \mathrm{mg}$ vs. $1,131 \pm 182$ $\mathrm{RLU} / \mathrm{s} / \mathrm{mg} ; \mathrm{n}=3-4 ; \mathrm{p}=0.0098)$. Meanwhile, angiotensin II treatment caused an increase in ROS formation $(1,625 \pm 105 \mathrm{RLU} / \mathrm{s} / \mathrm{mg} ; \mathrm{n}=2-4 ;$ pvs. ctrl. $>0.05)$. This increase was mitigated considerably by co-administration of G-1, although G-1 did not completely prevent angiotensin II-driven ROS formation (817 \pm 7 RLU/s/mg; $n=$ $2-4$; Pvs. angll = 0.0219; Pvs. G-1 > 0.05; Fig. 5b).

In an additional approach, the effect of G-1 and angiotensin II on HCASMC proliferation was quantified by an ELISA-based BrdU assay. G-1 reduced baseline HCASMC proliferation by $43.2 \pm 1.3 \%(n=9-15 ; p$ vs. ctrl. $<0.001)$, while angiotensin II enhanced it by $50.4 \pm 1.7 \%(n=5$; pvs. ctrl. $<0.001)$. During co-administration of both substances, G-1 and angiotensin II, HCASMC proliferation was markedly reduced compared to angiotensin II alone by $26.8 \pm 2.7 \%$; $n=16$; pvs. angll $<0.001$ ), yet slightly increased compared to G-1 alone ( $p_{\text {vs. G-1 }}=0.0382$; Fig. 5c).

\section{Discussion}

In the present study, we investigated the influence of the selective GPR30 agonist G1 on glucose tolerance, endothelial dysfunction, reactive oxygen species formation, and atherogenesis in the atherosclerotic $\mathrm{ApoE}^{-/-}$mouse model. Several studies have 
already addressed the role of GPR30 in diabetes, vasodilation, and atherogenesis using murine, porcine, and human models $[5,16,21]$. However, no study has yet investigated the vasoactive and anti-atherogenic properties of G-1 within the atherosclerotic $\mathrm{ApoE}^{-/-}$mouse model.

Our study demonstrates that G-1 improves endothelium-dependent vasorelaxation in ovariectomized $\mathrm{ApoE}^{-/-}$mice. This is accompanied by a significant decrease in ROS formation within the atherosclerotic vessel wall due to G-1 treatment. ROS are known to limit the endothelial availability of NO, thus mitigation of ROS might explain the improved vascular function following administration of G-1 [28]. In addition to reduced degradation of NO, its bioavailability is also increased by enhanced synthesis. Interestingly, Meyer and colleagues have demonstrated that G-1 causes the phosphorylation and activation of endothelial NO synthase (eNOS) in human endothelial cells [21]. A similar mechanism was observed in diabetic rats [16] and might also contribute to the improved vasorelaxation seen in the current atherosclerotic mouse model. Interestingly, both effects, mitigation of ROS and improvement of vasorelaxation were markedly more pronounced in ovariectomized female mice than in male mice, which may underline the potential pathophysiological relevance of these mechanisms in postmenopausal women.

The improvement in vascular relaxation capacity due to G-1 treatment was accompanied by a reduced atherosclerotic plaque burden in G-1- versus vehicletreated animals. While this is, to our knowledge, the first study to investigate the influence of $\mathrm{G}-1$ on atherogenesis in the $\mathrm{ApoE}^{-/-}$mouse model, one previous study has already investigated the influence of G-1 on atherogenesis in wildtype mice. This earlier report by Meyer and co-workers, who found a significant reduction in the 
atherosclerotic plaque burden of G-1-treated wildtype mice compared to vehicletreated controls, is corroborated by our data [21]. Our work extends the current knowledge on the effect of GPR30 signalling to the most commonly used atherosclerotic mouse model, which may facilitate future research in the field.

GPR30 has not only been shown to improve endothelial function and to promote atheroprotection, but GPR30 has also been reported to favorably modulate cardiovascular risk factors [29]. Consequently, we investigated the impact of G-1 on arterial blood pressure and blood glucose in the atherosclerotic $\mathrm{ApoE}^{-/-}$mouse model.

Interestingly, G-1 did not lower arterial blood pressure in the current study. This finding seems at odds with earlier reports on normotensive and hypertensive rats, in which an acute intravenous infusion of G-1, or its application over a short period of 2 weeks, lowered arterial blood pressure $[13,14,15]$. However, both, G-1 treatment over a prolonged period of time of 16 weeks and genetic disruption of GPR30 for up to 6 months, did not alter arterial blood pressure in mice [17,21], which is in line with our own data.

Furthermore, GPR30 agonism by G-1 has been demonstrated to lower blood glucose levels in diabetic rats [16] and genetic disruption of GPR30 signaling promotes hyperglycemia and visceral obesity in mice $[13,17]$. In the current study, G-1 greatly improved glucose tolerance in atherosclerotic mice of both sexes. These data extend our current knowledge of GPR30's role in glucose homeostasis to the atherosclerotic ApoE ${ }^{-/}$model. Earlier reports have demonstrated that $\mathrm{G}-1$ increases insulin secretion from human pancreatic islets and that genetic disruption of GPR30 diminishes insulin transcription and release in mice $[17,19,20]$. This mechanism might also apply in the 
$\mathrm{Apo}^{-/-}$mouse model, which would explain the improvement in glucose tolerance in the present study.

In an earlier study by Isensee and coworkers, gender differences in the expression pattern of GPR30 were carefully evaluated in C57BL/6J wildtype mice, i.e. the genetic background from which the $\mathrm{ApoE}^{-/}$mice used in our present study were derived [30]. Consistent with our findings, GPR30 was absent in the aortic tissue in this former study. While GPR30 is absent in large arteries, it is, however, expressed in other vascular beds, e.g. in the small arterioles of the vasa vasorum, in fine branches of the mesenteric arteries, as well as in vascular smooth muscle cells and pericytes in the brain and in both, human and porcine coronary artery smooth muscle cells $[30,31]$. Interestingly, there is currently no evidence for gender differences in the expression of GPR30 in any tissue [30]. Different receptor expression quantities between sexes are thus an unsuitable explanation for the clear gender-differences in the effect of G-1 on aortic endothelial function and atherogenesis, which are shown by our in vivo experiments. One may speculate that these differences are due to functional or expressional differences in other organs and cells that regulate glucose metabolism or ROS generation and not due to direct effects of G-1 on resident vascular cells in the murine aorta. Meanwhile, our in vitro experiments on human coronary artery smooth muscle cells do indicate direct effects of G-1 on AT1-receptor expression and on HCASCM proliferation.

Finally, the effect of G-1 on HCASMC biology was studied in vitro in order to gain mechanistic insights into how human atherogenesis might be influenced by GPR30signaling. As $\mathrm{G}-1$ has been reported to reduce the expression of the $\mathrm{AT}_{1}$ receptor in aortic tissue of rats [14] and given that $\mathrm{AT}_{1}$-receptor activation is a potent trigger of 
ROS formation [32], we studied whether G-1 counteracts AT ${ }_{1}$-receptor-induced ROS production and proliferation of HCASMC. Intriguingly, G-1 markedly reduced baseline ROS production by HCASMC and mitigated ROS production induced by angiotensin II. Similarly, G-1 diminished HCASMC proliferation and prevented its induction by angiotensin II. Additionally, our data demonstrate that G-1 promotes downregulation of the $\mathrm{AT}_{1}$ receptor in $\mathrm{HCASMC}$, which may explain the reduction in ROS and in HCASMC proliferation in vitro and which might promote atheroprotective effects in vivo.

Our data underline the vasculoprotective and anti-atherogenic properties of G-1, and its clinical use as an anti-atherosclerotic treatment appears to be compelling, especially in postmenopausal women. However, GPR30 has been implicated in the carcinogenesis of hormone-sensitive tumors, such as ovarian, breast, and cervical cancers, which might limit the clinical benefits of GPR30 agonists [33,34]. Although, other studies have reported vasculoprotective effects for two selective estrogen receptor modulators (SERM), raloxifene and lasofoxifene, which are used in the therapy for breast cancer and osteoporosis $[5,35,36]$. These substances antagonize ER $\alpha$ and ER $\beta$ but act as GPR30 agonists. Similar compounds could be used to produce favorable cardiovascular effects without the carcinogenic side effects.

\section{Conclusions:}

Taken together, our data indicate that G-1 improves glucose tolerance and atheroprotection in $\mathrm{ApoE}^{-/-}$mice. G-1 mitigates ROS, improves vasorelaxation, and 
diminishes atherosclerosis. These effects are more pronounced in female ovariectomized $\mathrm{ApoE}^{-/-}$mice. GPR30 agonism might thus be a compelling treatment strategy against atherosclerosis, particularly in postmenopausal women. 
Acknowledgement:

We thank Theresa Schmitz, Anna Flender, and Kathrin Paul-Krahé for their excellent technical assistance. We are grateful to Dr. Meghan Campbell for the careful revision of the manuscript.

Conflict of interest:

None. 
References:

1. Olszanecka A, Kawecka-Jaszcz K, Czarnecka D. Association of free testosterone and sex hormone binding globulin with metabolic syndrome and subclinical atherosclerosis but not blood pressure in hypertensive perimenopausal women. Arch Med Sci. 2016; 12:521-528.

2. Whayne TF Jr, Mukherjee D. Women, the menopause, hormone replacement therapy and coronary heart disease. Curr Opin Cardiol 2015; 30:432-438.

3. Wilkenfeld SR, Lin C, Frigo DE. Communication between genomic and nongenomic signaling events coordinate steroid hormone actions. Steroids. 2018; 133:27.

4. Razandi M, Oh P, Pedram A, Schnitzer J, Levin ER. ERs associate with and regulate the production of caveolin: implications for signaling and cellular actions. Mol Endocrinol 2002; 16:100-115.

5. Meyer MR, Prossnitz ER, Barton M. The G protein-coupled estrogen receptor GPER/GPR30 as a regulator of cardiovascular function. Vascul Pharmacol 2011; $55: 17-25$. 
6. Schwartz N, Verma A, Bivens CB, Schwartz Z, Boyan BD. Rapid steroid hormone actions via membrane receptors. Biochim Biophys Acta 2016; 1863:2289-2298.

7. Takada $Y$, Kato $C$, Kondo S, Korenaga R, Ando J. Cloning of cDNAs encoding G protein-coupled receptor expressed in human endothelial cells exposed to fluid shear stress. Biochem Biophys Res Commun 1997; 240:737-741.

8. Broughton BR, Miller AA, Sobey CG. Endothelium-dependent relaxation by G protein-coupled receptor 30 agonists in rat carotid arteries. Am J Physiol Heart Circ Physiol 2010; 298:H1055-H1061.

9. Bologa CG, Revankar CM, Young SM, et al. Virtual and biomolecular screening converge on a selective agonist for GPR30. Nat Chem Biol 2006; 2:207-212

10. Dennis MK, Burai R, Ramesh C, et al. In vivo effects of a GPR30 antagonist. Nat Chem Biol 2009; 5:421-427.

11. Meyer MR, Haas E, Prossnitz ER, Barton M. Non-genomic regulation of vascular cell function and growth by estrogen. Mol Cell Endocrinol 2009; 308:9-16. 
12. Koganti S. Cardioprotective role of G-Protein Coupled Estrogen Receptor 1 (GPER1). Mol Membr Biol 2015; 32:35-38.

13. Haas E, Bhattacharya I, Brailoiu E, et al. Regulatory role of G protein-coupled estrogen receptor for vascular function and obesity. Circ Res 2009; 104:288-291.

14. Lindsey SH, Cohen JA, Brosnihan KB, Gallagher PE, Chappell MC. Chronic treatment with the $\mathrm{G}$ protein-coupled receptor 30 agonist $\mathrm{G}-1$ decreases blood pressure in ovariectomized mRen2.Lewis rats. Endocrinology 2009; 150:3753-3758.

15. Lindsey SH, Carver KA, Prossnitz ER, Chappell MC. Vasodilation in response to the GPR30 agonist G-1 is not different from estradiol in the mRen2.Lewis female rat. J Cardiovasc Pharmacol 2011; 57:598-603.

16. Li ZL, Liu JC, Liu SB, Li XQ, Yi DH, Zhao MG. Improvement of vascular function by acute and chronic treatment with the GPR30 agonist G1 in experimental diabetes mellitus. PLoS One 2012; 7:e38787.

17. Mårtensson UE, Salehi SA, Windahl S, et al. Deletion of the G protein-coupled receptor 30 impairs glucose tolerance, reduces bone growth, increases blood pressure, and eliminates estradiol-stimulated insulin release in female mice. Endocrinology 2009; 150:687-698. 
18. Feng Y, Madungwe NB, da Cruz Junho CV, Bopassa JC. Activation of G proteincoupled oestrogen receptor 1 at the onset of reperfusion protects the myocardium against ischemia/reperfusion injury by reducing mitochondrial dysfunction and mitophagy. Br J Pharmacol 2017; 174:4329-4344.

19. Kumar R, Balhuizen A, Amisten S, Lundquist I, Salehi A. Insulinotropic and antidiabetic effects of $17 \beta$-estradiol and the GPR30 agonist G-1 on human pancreatic islets. Endocrinology 2011; 152:2568-2579.

20. Sharma G, Hu C, Brigman JL, Zhu G, Hathaway HJ, Prossnitz ER. GPER deficiency in male mice results in insulin resistance, dyslipidemia, and a proinflammatory state. Endocrinology 2013; 154:4136-4145.

21. Meyer MR, Fredette NC, Howard TA, et al. G protein-coupled estrogen receptor protects from atherosclerosis. Sci Rep 2014; 4:7564.

22. Meir KS, Leitersdorf E. Atherosclerosis in the apolipoprotein-E-deficient mouse: a decade of progress. Arterioscler Thromb Vasc Biol 2004; 24:1006-1014. 
23. Tiyerili V, Müller CF, Fung S, Panek D, Nickenig G, Becher UM. Estrogen improves vascular function via peroxisome-proliferator-activated-receptor- $\gamma$. J Mol Cell Cardiol 2012; 53:268-276.

24. Jehle J, Hoyer FF, Schöne B, et al. Myeloid-Specific Deletion of Diacylglycerol Lipase a Inhibits Atherogenesis in ApoE-Deficient Mice. PLoS One 2016; 11:e0146267.

25. Jehle J, Müller CFH, Aksoy A, Zimmer S, Nickenig G, Tiyerili V. Genetic disruption of multidrug resistance-associated protein 1 improves endothelial function and attenuates atherosclerosis in MRP1-/- LDLr-/- double knockout mice. Arch Med Sci. 2017; 13:930-936.

26. Jehle J, Tiyerili V, Adler S, Groll K, Nickenig G, Becher UM. Atheroprotective effects of $17 \beta$-oestradiol are mediated by peroxisome proliferator-activated receptor $Y$ in human coronary artery smooth muscle cells. Arch Med Sci Atheroscler Dis. 2020; 5:e118-e126.

27. Jehle J, Schöne B, Bagheri S, et al. Elevated levels of 2-arachidonoylglycerol promote atherogenesis in ApoE-/- mice. PLoS One 2018; 13:e0197751. 
28. Virdis A, Taddei S. Endothelial Dysfunction in Resistance Arteries of Hypertensive Humans: Old and New Conspirators. J Cardiovasc Pharmacol 2016; 67:451-457.

29. Atkins PW, Perez HA, Spence JD, Munoz SE, Armando LJ, Garcia NH. Increased carotid plaque burden in patients with family medical history of premature cardiovascular events in the absence of classical risk factors. Arch Med Sci. 2019; 15:1388-1396.

30. Isensee J, Meoli L, Zazzu V, et al. Expression pattern of G protein-coupled receptor 30 in LacZ reporter mice. Endocrinology. 2009; 150:1722-1730.

31. Li F, Yu X, Szynkarski CK, et al. Activation of GPER Induces Differentiation and Inhibition of Coronary Artery Smooth Muscle Cell Proliferation. PLoS One. 2013; 8:e64771.

32. Nickenig G. Central role of the AT(1)-receptor in atherosclerosis. J Hum Hypertens 2002; 16 Suppl 3:S26-33.

33. Wang D, Hu L, Zhang G, Zhang L, Chen C. G protein-coupled receptor 30 in tumor development. Endocrine 2010; 38:29-37. 
34. Yang W, Tan W, Zheng J, Zhang B, Li H, Li X. MEHP promotes the proliferation of cervical cancer via GPER mediated activation of Akt. Eur J Pharmacol 2018; 824:11-16.

35. Collins P, Mosca L, Geiger MJ, et al. Effects of the selective estrogen receptor modulator raloxifene on coronary outcomes in the Raloxifene Use for The Heart trial: results of subgroup analyses by age and other factors. Circulation 2009; 119:922930.

36. Ensrud K, LaCroix A, Thompson JR, et al. Lasofoxifene and cardiovascular events in postmenopausal women with osteoporosis: Five-year results from the Postmenopausal Evaluation and Risk Reduction with Lasofoxifene (PEARL) trial. Circulation 2010; 122:1716-1724. 
Tables:

Table 1. Overview of TaqMan® probes used in this study.

\begin{tabular}{llll}
\hline $\begin{array}{l}\text { TaqMan® Gene } \\
\text { Expression Assay } \\
\text { ID }\end{array}$ & Target Gene & Vendor & Cat Num \\
\hline Mm01194815_m1 & GPR30 & $\begin{array}{l}\text { Thermo Fisher } \\
\text { Scientific Inc. }\end{array}$ & 4331182 \\
Mm00558224_s1 & $\begin{array}{l}\text { Angiotensin II receptor } \\
\text { type 1 }\end{array}$ & $\begin{array}{l}\text { Thermo Fisher } \\
\text { Scientific Inc. }\end{array}$ & 4331182 \\
Hs03003631_g1 & Eukaryotic 18S rRNA & $\begin{array}{l}\text { Thermo Fisher } \\
\text { Scientific Inc. }\end{array}$ & 4331182 \\
Hs05043708_s1 & $\begin{array}{l}\text { Angiotensin II receptor } \\
\text { type 1 }\end{array}$ & $\begin{array}{l}\text { Thermo Fisher } \\
\text { Scientific Inc. }\end{array}$ & 4331182 \\
\hline
\end{tabular}


Table 2. Clinical parameters. Clinical parameters were assessed separately for male and for female ovariectomized mice at the end of the feeding period. Plasma cholesterol, body weight, arterial blood pressure, and heart rate were similar between the treatment groups for both sexes. Data are presented as the mean \pm standard error of the mean; $n=4-5$. OVX, ovariectomized.

\begin{tabular}{|c|c|c|c|c|}
\hline & $\begin{array}{l}\text { Total } \\
\text { cholesterol } \\
{[\mathrm{mg} / \mathrm{dl}]}\end{array}$ & $\begin{array}{l}\text { Body weight } \\
\text { [g] }\end{array}$ & $\begin{array}{l}\text { Systolic blood } \\
\text { pressure } \\
{[\mathrm{mmHg}]}\end{array}$ & $\begin{array}{l}\text { Heart rate } \\
\text { [beats / } \mathrm{min} \text { ] }\end{array}$ \\
\hline \multicolumn{5}{|l|}{ Female (OVX) } \\
\hline ApoE ${ }^{-/-}$ & $1426 \pm 87$ & $25.5 \pm 1$ & $127 \pm 23$ & $702 \pm 39$ \\
\hline $\mathrm{ApoE}^{-/-}+\mathrm{G}-1$ & $1274 \pm 121$ & $25.9 \pm 1$ & $129 \pm 72$ & $709 \pm 39$ \\
\hline \multicolumn{5}{|l|}{ Male } \\
\hline ApoE ${ }^{-/-}$ & $1233 \pm 32$ & $30.8 \pm 2$ & $130 \pm 65$ & $783 \pm 78$ \\
\hline ApoE $^{-/-}+$G-1 & $1258 \pm 84$ & $31.6 \pm 2$ & $132 \pm 59$ & $644 \pm 46$ \\
\hline
\end{tabular}


Figure legends:

Figure 1. Schematic of the experimental protocol. At the age of 8 weeks, female $\mathrm{ApoE}^{-/}$mice were ovariectomized. After 12 weeks, female and male mice were fed a high-fat and high-cholesterol diet and treated with s.c. injections of either G-1 [50 $\mu \mathrm{g} / \mathrm{kg}$ bodyweight] or vehicle (DMSO [0.5\% (v/v)]). Fasting blood glucose levels and glucose tolerance were assessed at day 43 , blood pressure and heart rate were assessed at days 44-49. Mice were sacrificed at day 50 before endothelial function and reactive oxygen species formation were assessed ex vivo.

Figure 2. Assessment of blood glucose levels and glucose tolerance in vivo. Glucose tolerance was assessed in atherosclerotic ApoE $\mathrm{A}^{-/}$mice after 6 weeks of high-fat diet and G-1- versus vehicle (DMSO) treatment. The fasting blood glucose level was significantly reduced in G-1-treated female mice compared to vehicletreated controls (a). G-1-induced reduction in fasting blood glucose levels did not reach statistical significance in male mice (b). Upon ipGTT, glucose tolerance was improved in both female and male mice following G-1 treatment (c, d). Data are presented as the mean \pm standard error of the mean; $n=4-5 ;{ }^{*}, p<0.05 ;{ }^{* *}, p<$ 0.01. G-1, GPR30 agonist; ipGTT, intraperitoneal glucose tolerance test; DMSO, dimethyl sulfoxide; OVX, ovariectomized.

Figure 3. Assessment of endothelium-dependent vasodilation and ROS production in vivo. Isolated aortic rings of $\mathrm{G}-1$-treated $\mathrm{ApoE}^{-/-}$mice (blue squares) and vehicle-treated controls (DMSO, black circles) were exposed to increasing concentrations of phenylephrine to elicit vasoconstriction $(a-b)$ and subsequently to 
carbachol to measure endothelium-dependent vasorelaxation. Endothelial function was significantly improved in G-1-treated female $\mathrm{ApoE}^{-/-}$mice compared to vehicletreated controls (c) but not in male $\mathrm{ApoE}^{-/}$mice (d). The improvement in vascular function was mirrored by mitigation of ROS by G-1 in the female cohort, as assessed by L-012 enhanced chemiluminescence (e). ROS production in male mice was not significantly reduced by G-1 (f). Data are presented as the mean \pm standard error of the mean; $n=5-6 ;{ }^{*}, p<0.05 ;{ }^{*}, p<0.01$. DMSO, dimethyl sulfoxide; G-1, GPR30 agonist; OVX, ovariectomized; RLU, relative light units; ROS, reactive oxygen species.

Figure 4. Assessment of the atherosclerotic plaque burden. Atherosclerotic plaques were visualized in frozen sections through the aortic sinus by oil red $\mathrm{O}$ staining. Relative atherosclerotic plaque burden was calculated as the ratio between total plaque area and the area of the vessel wall. G-1 caused a significant reduction in the atherosclerotic plaque burden of female $\mathrm{ApoE}^{-/-}$mice (a). In male mice, atherosclerotic plaque volume was slightly reduced by $\mathrm{G}-1$ without reaching statistical significance (b). Data are presented as the mean \pm standard error of the mean; $\mathrm{n}=4$ $6 ;{ }^{*}, p<0.05$. Scale bar, $500 \mu \mathrm{m}$. DMSO, dimethyl sulfoxide; G-1, GPR30 agonist; OVX, ovariectomized.

Figure 5. Quantification of AT1 receptor mRNA expression, ROS production, and cell proliferation upon G-1 stimulation in HCASMC. AT1 receptor mRNA expression of HCASMC was assessed by qPCR upon stimulation with G-1 [1 $\mu \mathrm{M}]$ for 4 hours (a). ROS formation was assessed by the L-012 assay (b). HCASMC 
proliferation was assessed using an ELISA-based BrdU staining (c). Data are presented as the mean \pm standard error of the mean; $n=2-16 ;{ }^{*}, p<0.05 ;{ }^{*}, p<$ 0.01. Ang 2, angiotensin II; $A T_{1}$ receptor, angiotensin II type 1 receptor; BrdU, 5bromo-2'-deoxyuridine; DMSO, dimethyl sulfoxide; G-1, GPR30 agonist; HCASMC, human coronary artery smooth muscle cells; RLU, relative light units; ROS, reactive oxygen species.

Supplementary Figure S1. Expression of GPR30 in the murine abdominal aorta.

Frozen sections through the abdominal aorta of female (a-b) and male (c-d) ApoE ${ }^{-1-}$ mice. Panels a and c depict merged images of DAPI staining (blue, nuclei), elastic fibers (green) and GPR30 (red). Panels $b$ and d show red GPR30 staining only. Both female and male mice show no specific staining for GPR30. Scale bar, $100 \mu \mathrm{m}$. ApoE, Apolipoprotein E. 

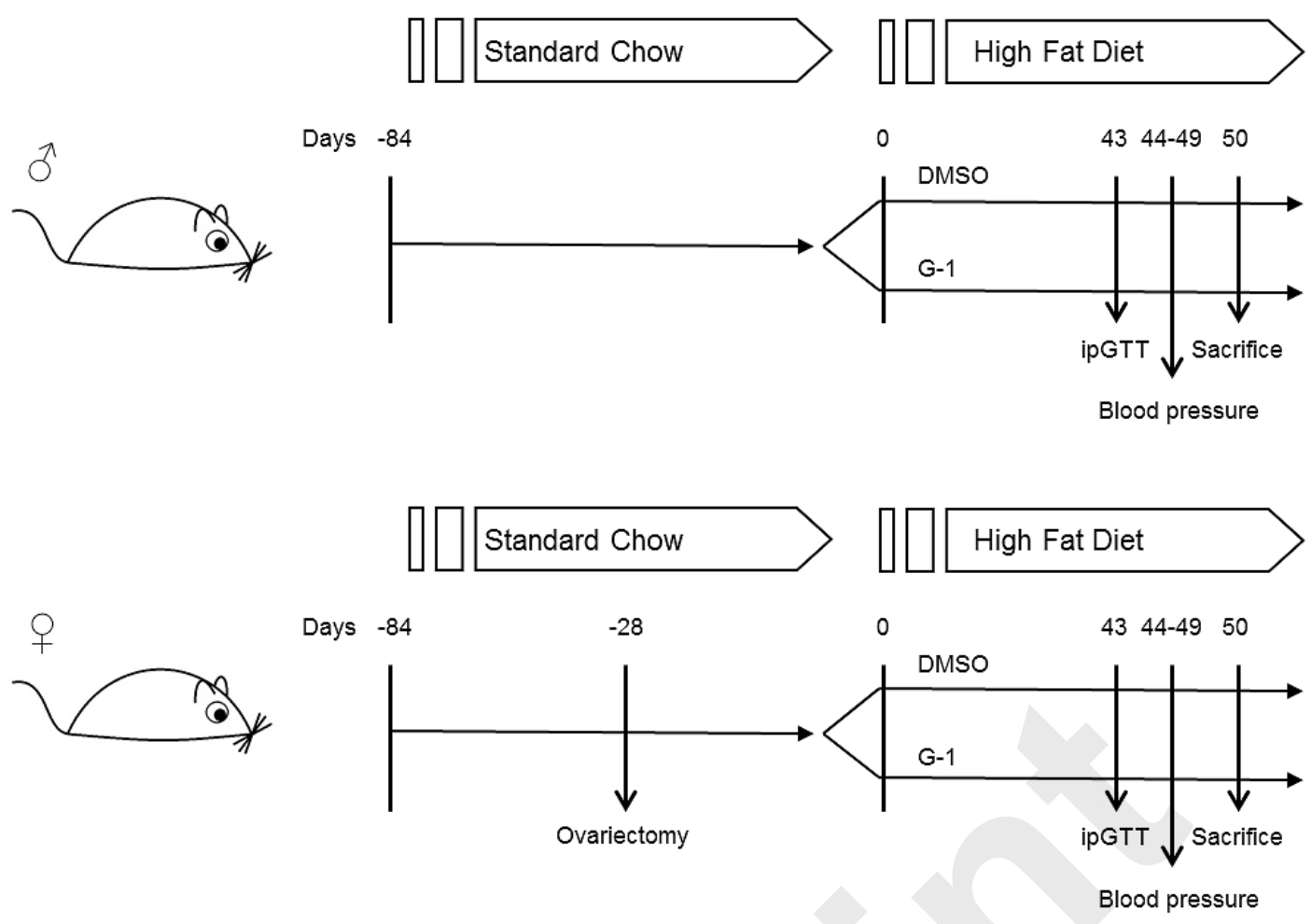

Figure 1. Schematic of the experimental protocol. At the age of 8 weeks, female ApoE-/mice were ovariectomized. After 12 weeks, female and male mice were fed a high-fat and high-cholesterol diet and treated with s.c. injections of either G-1 [50 $\mu \mathrm{g} / \mathrm{kg}$ bodyweight] or vehicle (DMSO $[0.5 \%(\mathrm{v} / \mathrm{v})]$ ). Fasting blood glucose levels and glucose tolerance were assessed at day 43 , blood pressure and heart rate were assessed at days 44-49. Mice were sacrificed at day 50 before endothelial function and reactive oxygen species formation were assessed ex vivo. 

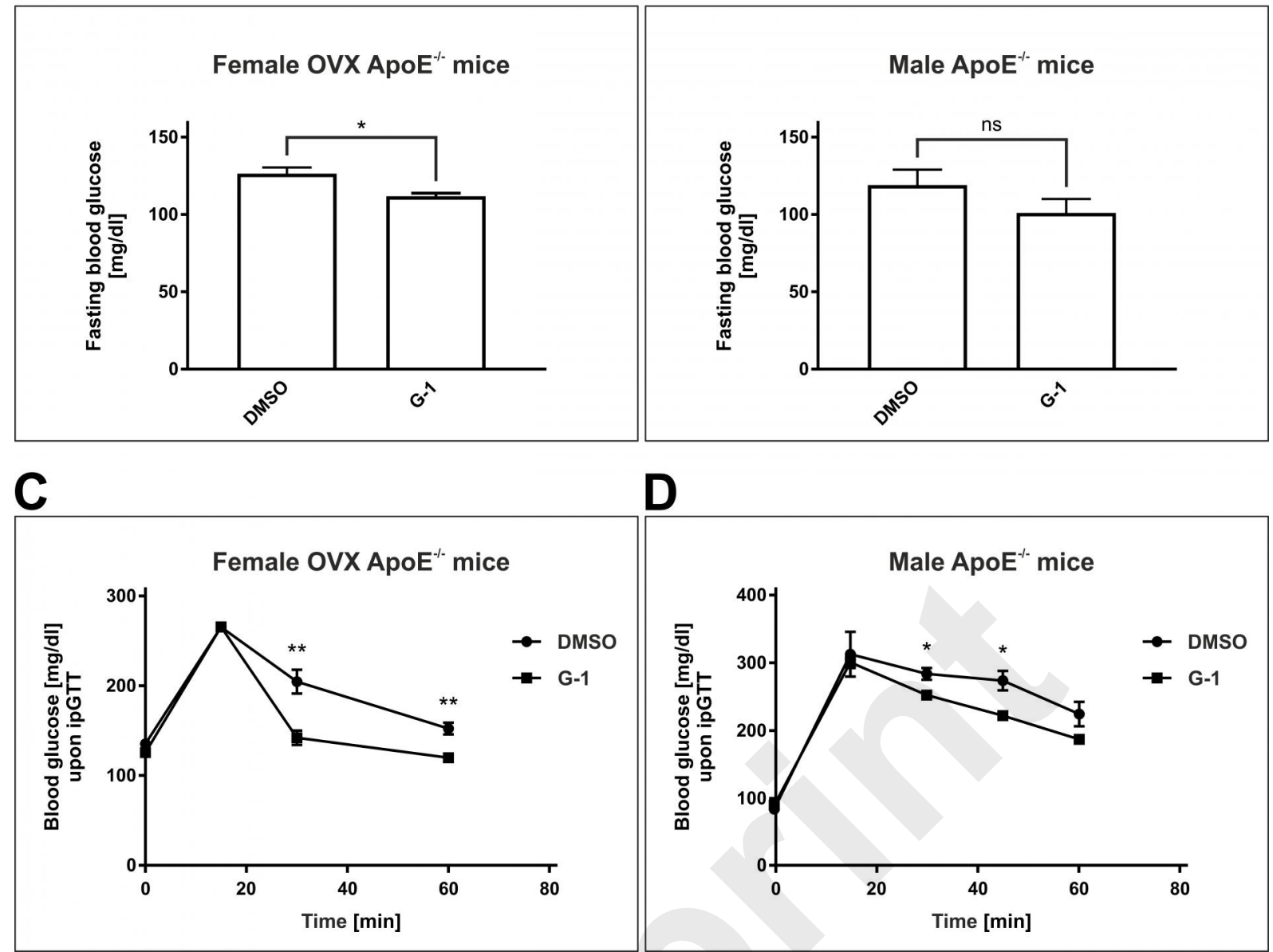

D

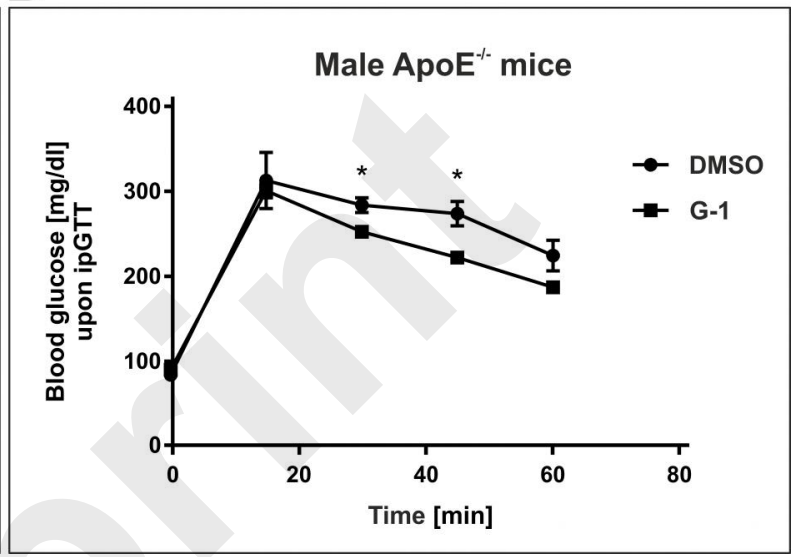

Figure 2. Assessment of blood glucose levels and glucose tolerance in vivo. Glucose tolerance was assessed in atherosclerotic ApoE-/- mice after 6 weeks of high-fat diet and G-1- versus vehicle (DMSO) treatment. The fasting blood glucose level was significantly reduced in G-1-treated female mice compared to vehicle-treated controls (a). G-1-induced reduction in fasting blood glucose levels did not reach statistical significance in male mice (b). Upon ipGTT, glucose tolerance was improved in both female and male mice following G-1 treatment (c, d). Data are presented as the mean \pm standard error of the mean; $n=4-5$; ${ }^{*}, p<0.05 ;{ }^{* *}, p<0.01$. G-1, GPR30 agonist; ipGTT, intraperitoneal glucose tolerance test; DMSO, dimethyl sulfoxide; OVX, ovariectomized. 

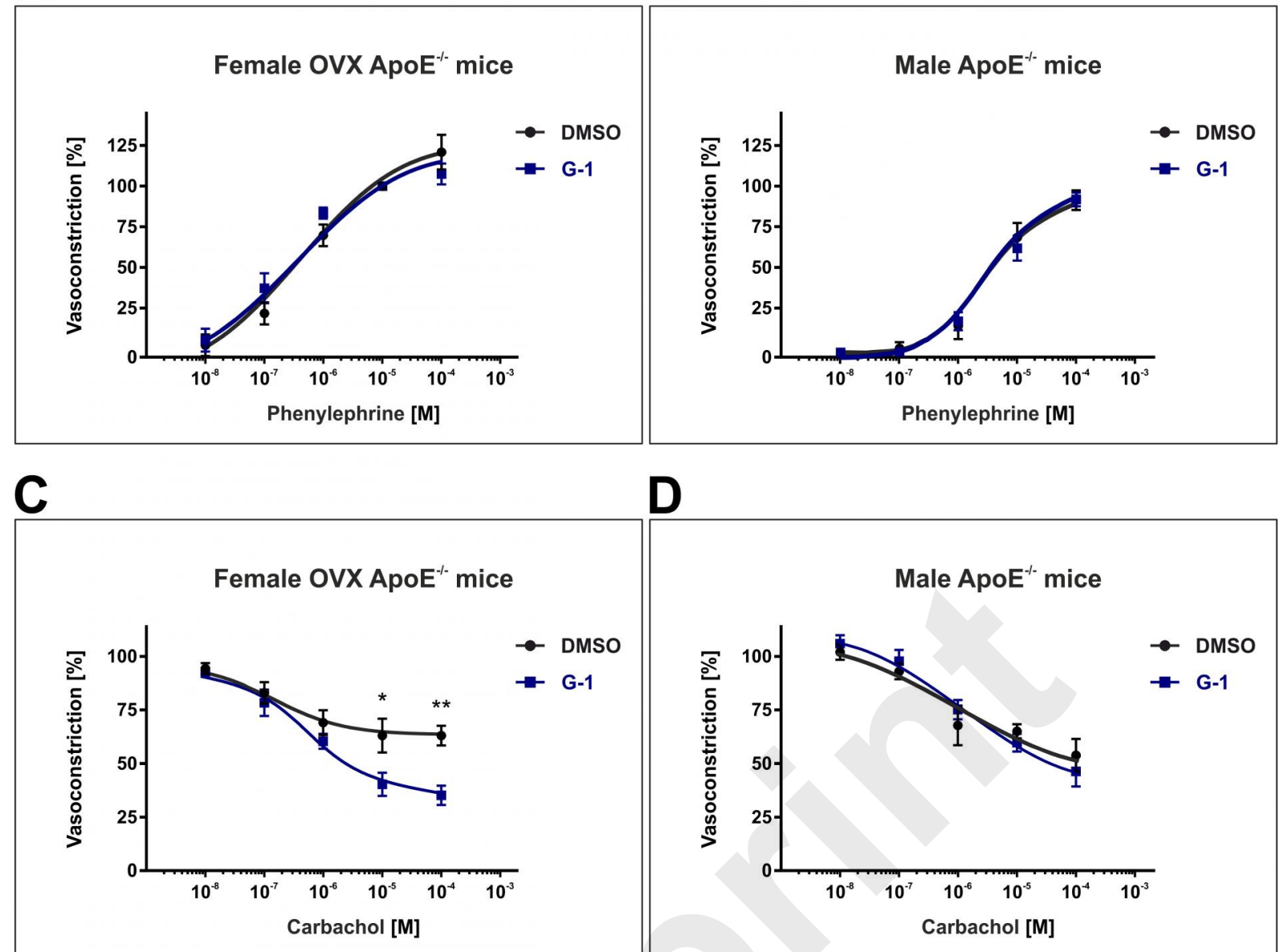

D

$\mathbf{E}$

$\mathbf{F}$
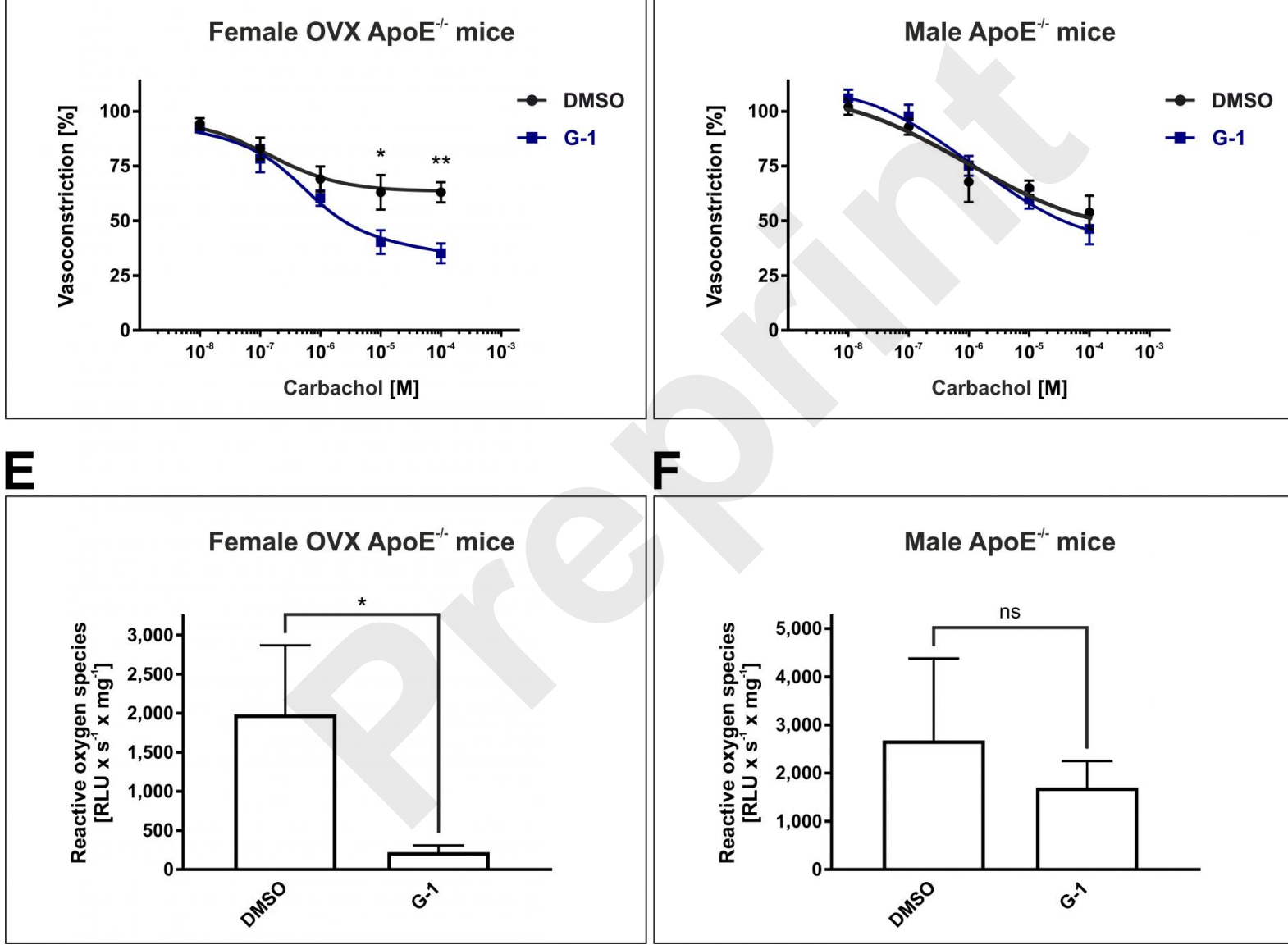

Figure 3. Assessment of endothelium-dependent vasodilation and ROS production in vivo. Isolated aortic rings of G-1-treated ApoE-/- mice (blue squares) and vehicle-treated controls (DMSO, black circles) were exposed to increasing concentrations of phenylephrine to elicit vasoconstriction (a-b) and subsequently to carbachol to measure endothelium-dependent vasorelaxation. Endothelial function was significantly improved in G-1-treated female ApoE-/- mice compared to vehicle-treated controls (c) but not in male ApoE-/- mice (d). The improvement in vascular function was mirrored by mitigation of ROS by G-1 in the female cohort, as assessed by L-012 enhanced chemiluminescence (e). ROS production in male mice was not significantly reduced by G-1 (f). Data are presented as the mean \pm standard error of the mean; $n=5-6 ;{ }^{*}, p<0.05 ;{ }^{* *}, p<0.01$. DMSO, dimethyl sulfoxide; G-1, GPR30 
agonist; OVX, ovariectomized; RLU, relative light units; ROS, reactive oxygen species. 


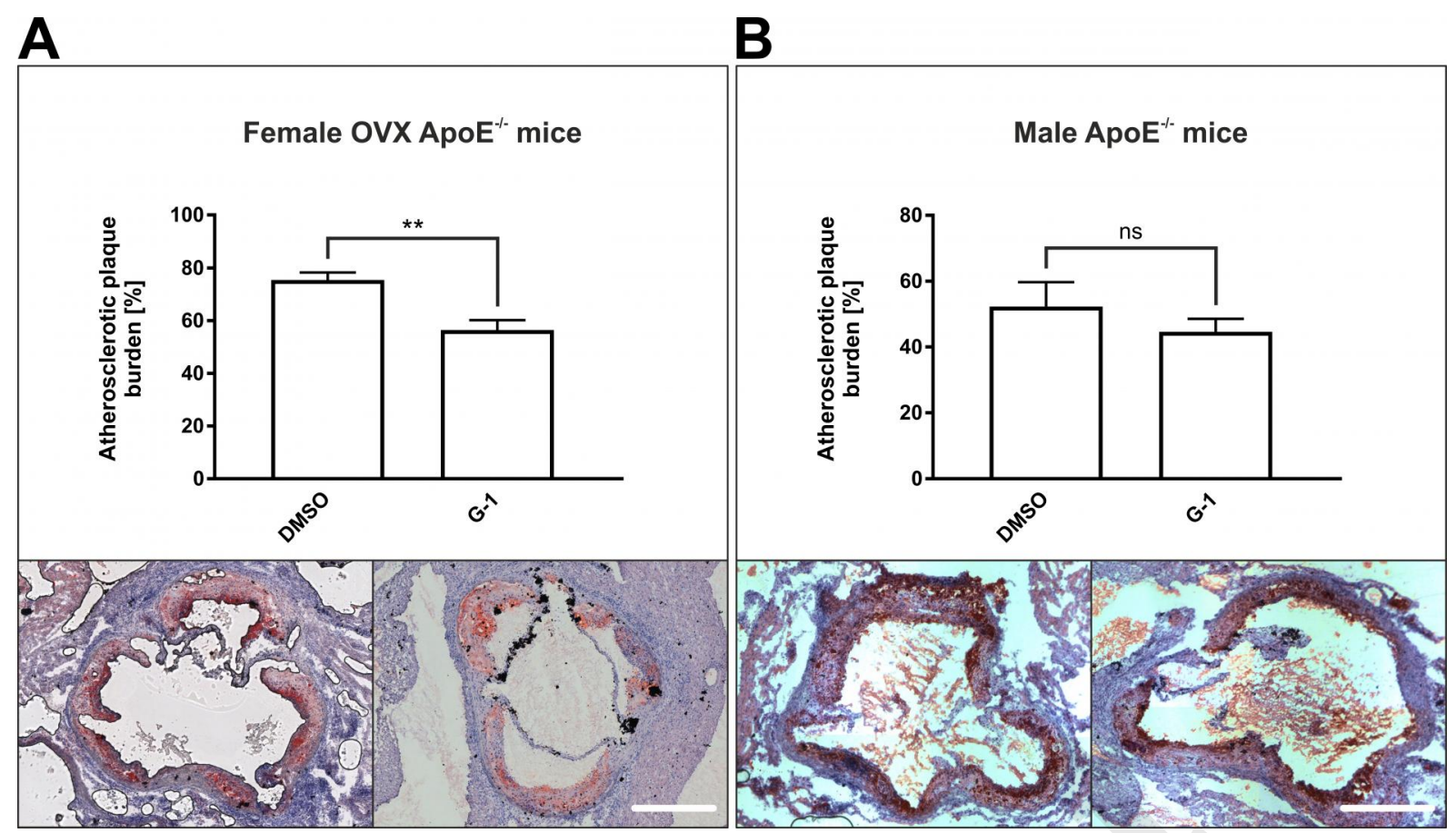

Figure 4. Assessment of the atherosclerotic plaque burden. Atherosclerotic plaques were visualized in frozen sections through the aortic sinus by oil red $O$ staining. Relative atherosclerotic plaque burden was calculated as the ratio between total plaque area and the area of the vessel wall. G-1 caused a significant reduction in the atherosclerotic plaque burden of female ApoE-/- mice (a). In male mice, atherosclerotic plaque volume was slightly reduced by G-1 without reaching statistical significance (b). Data are presented as the mean \pm standard error of the mean; $n=4-6 ;{ }^{*}, p<0.05$. Scale bar, $500 \mu \mathrm{m}$. DMSO, dimethyl sulfoxide; G-1, GPR30 agonist; OVX, ovariectomized. 
B

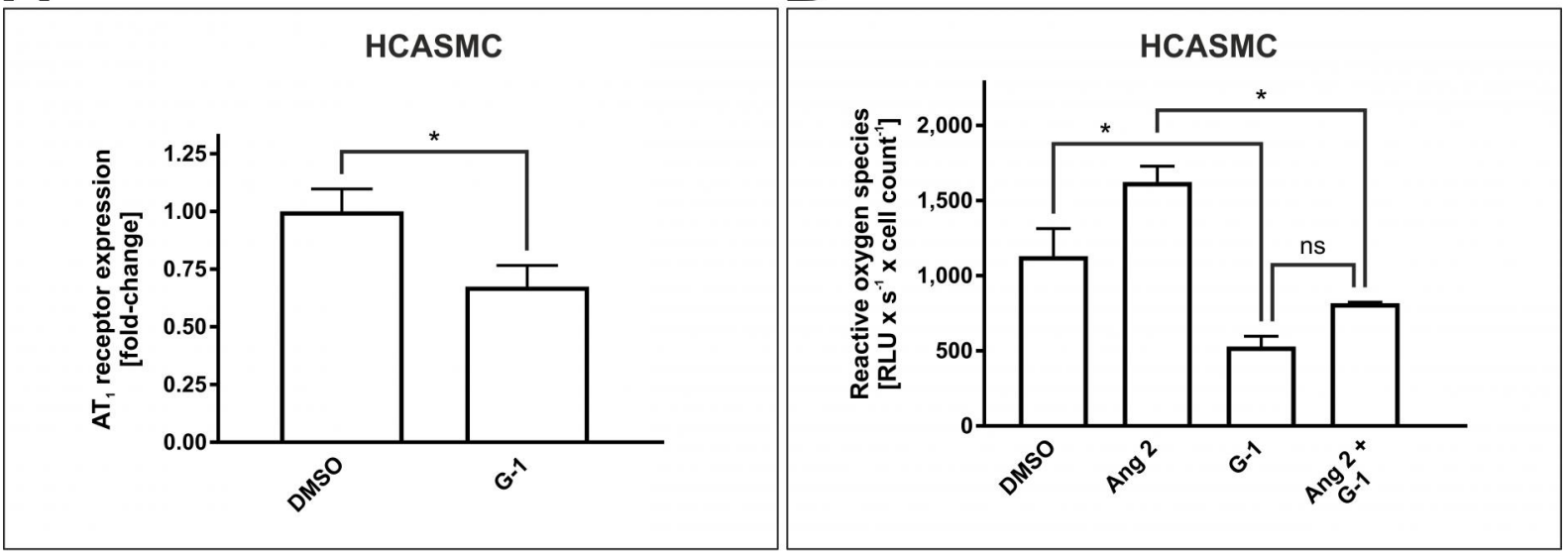

C

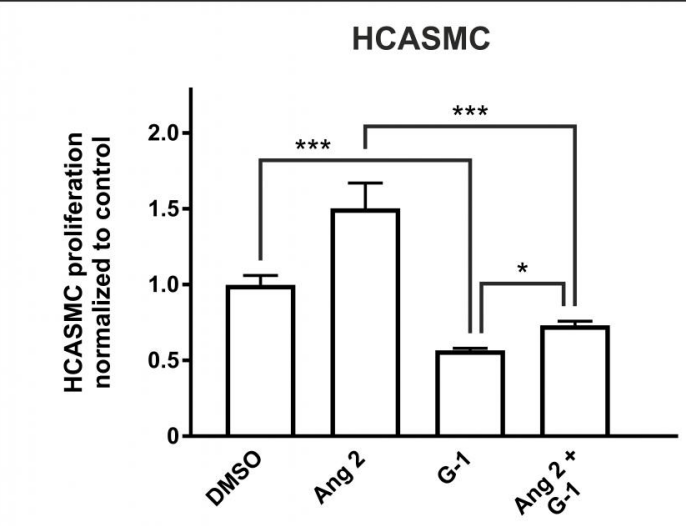

Figure 5. Quantification of AT1 receptor mRNA expression, ROS production, and cell proliferation upon G-1 stimulation in HCASMC. AT1 receptor mRNA expression of HCASMC was assessed by qPCR upon stimulation with G-1 [1 $\mu \mathrm{M}$ ] for 4 hours (a). ROS formation was assessed by the L-012 assay (b). HCASMC proliferation was assessed using an ELISA-based BrdU staining (c). Data are presented as the mean \pm standard error of the mean; $\mathrm{n}=2-16 ;{ }^{*}, \mathrm{p}<0.05 ;{ }^{* *}, \mathrm{p}<0.01$. Ang 2, angiotensin II; AT1 receptor, angiotensin II type 1 receptor; BrdU, 5-bromo-2'-deoxyuridine; DMSO, dimethyl sulfoxide; G-1, GPR30 agonist; HCASMC, human coronary artery smooth muscle cells; RLU, relative light units; ROS, reactive oxygen species. 

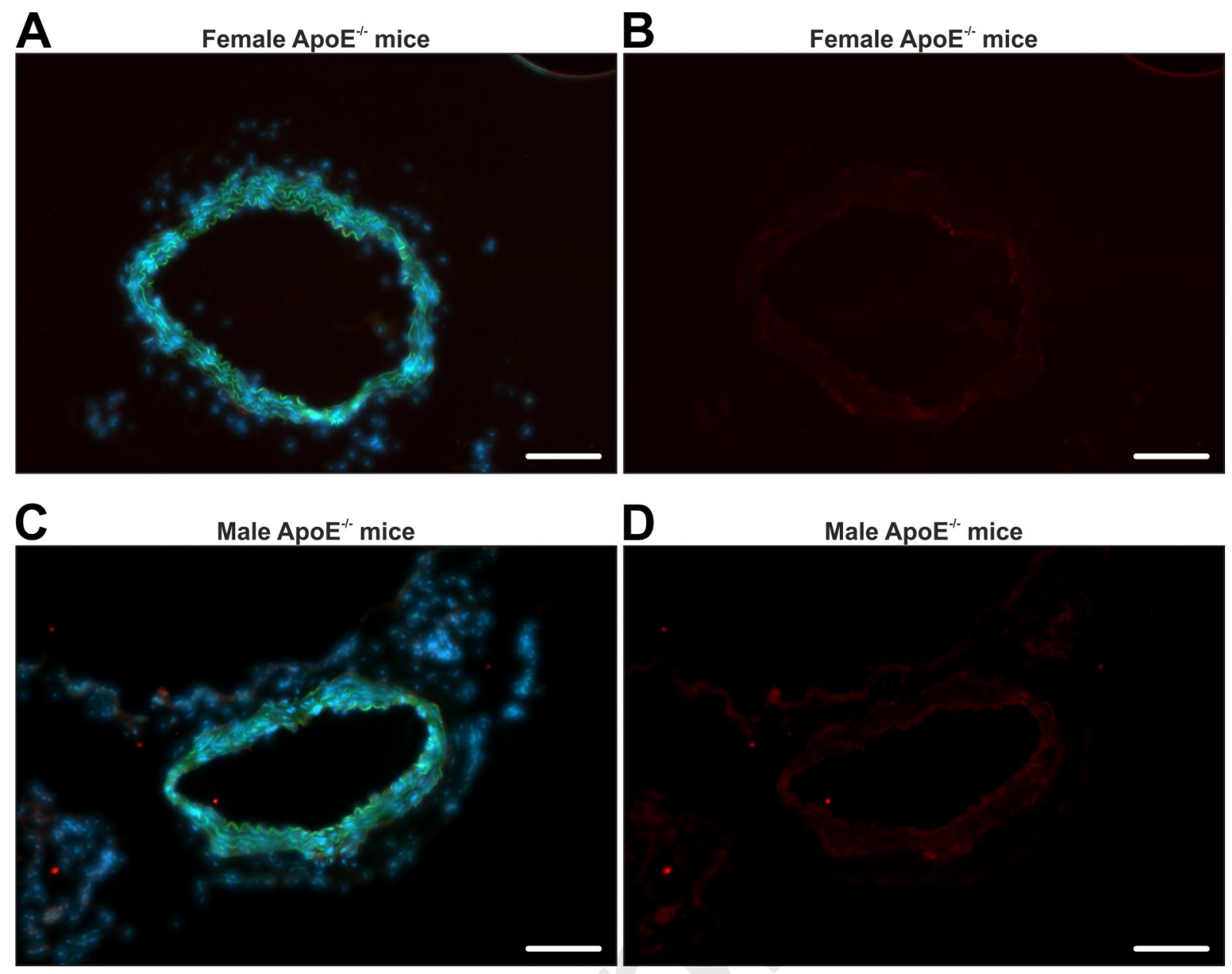

Supplementary Figure S1. Expression of GPR30 in the murine abdominal aorta.

Frozen sections through the abdominal aorta of female (a-b) and male (c-d) ApoE-/- mice. Panels a and $c$ depict merged images of DAPI staining (blue, nuclei), elastic fibers (green) and GPR30 (red). Panels b and d show red GPR30 staining only. Both female and male mice show no specific staining for GPR30. Scale bar, $100 \mu \mathrm{m}$. ApoE, Apolipoprotein E. 